\title{
Effect of the Chemical Composition of Free-Terpene Hydrocarbons Essential Oils on Antifungal Activity
}

\author{
Ghada Ben Salha ${ }^{1,2,3}$, René Herrera Díaz ${ }^{1}$, Olfa Lengliz ${ }^{2,4}$, Manef Abderrabba ${ }^{2}$ \\ and Jalel Labidi $1, * \mathbb{C}$
}

1 Chemical and Environmental Engineering Department, University of the Basque Country UPV/EHU, Plaza Europa, 1, 20018 Donostia-San Sebastián, Spain; bensalhaghadaangel@gmail.com (G.B.S.); reneherdiaz@gmail.com (R.H.D.)

2 Laboratory Materials, Molecules and Application, Preparatory Institute for Scientific and Technical Studies, Marsa 2070, Tunisia; olfalenglizridene@gmail.com (O.L.); abderrabbamanef@gmail.com (M.A.)

3 Faculty of Sciences of Tunisia, University of Tunisia El Manar, Farhat Hached University Campus PB 94-Rommana, Tunis 1068, Tunisia

4 University of Carthage, National Institute of Applied Science and Technology, BP 676, CEDEX, Tunis 1080, Tunisia

* Correspondence: jalel.labidi@ehu.eus; Tel.: +34-943017178

Academic Editor: Derek J. McPhee

Received: 21 August 2019; Accepted: 28 September 2019; Published: 29 September 2019

\begin{abstract}
In this study, Carum carvi L. essential oil (CEO) and Origanum majorana L. essential oil (MEO) was steam-distillated under reduced pressure. We henceforth obtained three fractions for each essential oil: $\mathrm{CF}_{1}, \mathrm{CF}_{2}, \mathrm{CF}_{3}, \mathrm{MF}_{1}, \mathrm{MF}_{2}$, and $\mathrm{MF}_{3}$. Then, these fractions were characterized using the gas chromatography-mass spectrometry (GC-MS) technique. The results indicated that some fractions were rich in oxygenated compounds (i.e., $\mathrm{CF}_{2}, \mathrm{CF}_{3}, \mathrm{MF}_{2}$, and $\mathrm{MF}_{3}$ ) with concentrations ranging from $79.21 \%$ to $98.56 \%$. Therefore, the influence of the chemical composition of the essential oils on their antifungal activity was studied. For this purpose, three food spoilage fungi were isolated, identified, and inoculated in vitro, in order to measure the antifungal activity of CEO, MEO, and their fractions. The results showed that stronger fungi growth inhibitions (FGI) (above 95\%) were found in fractions with higher percentages of oxygenated compounds, especially with (-)-carvone and terpin-4-ol as the major components. Firstly, this work reveals that the free-terpenes hydrocarbons fractions obtained from MEO present higher antifungal activity than the raw essential oil against two families of fungi. Then, it suggests that the isolation of (-)-carvone $(97.15 \pm 55.97 \%)$ from CEO via vacuum distillation can be employed successfully to improve antifungal activity by killing fungi $(\mathrm{FGI}=100 \%)$. This study highlights that separation under reduced pressure is a simple green method to obtain fractions or to isolate compounds with higher biological activity useful for pharmaceutical products or natural additives in formulations.
\end{abstract}

Keywords: Carum carvi L.; Origanum majorana L.; (-)-carvone; terpin-4-ol; antifungal activity; free-terpenes hydrocarbons

\section{Introduction}

Over the last decade, several studies have shown the potential of using essential oils (EOs) as complementary medicine, i.e., for fungal diseases treatments. It is worth noting that most of these substances were declared as alternatives to synthetic fungicides from a natural origin [1-3]. Several studies identified EOs from carum (Carum carvi L.) (CEO) and origanum (Origanum majorana L.) (MEO) as potential antifungal agents against molds and food spoilage fungi [4-6]. However, there are not enough studies that clearly describe the effect of different molecules found in EOs and which 
could be effective as antifungal agents. Generally, these natural products are complex mixtures of terpenes (terpenes hydrocarbons and oxygenated components) with a variable degree of lipophilic and hydrophilic compounds [7]. It has been proven that the physical nature of any oxygenated compound favors the penetration to the fungi cell membrane, which increases the antifungal effect [8,9]. However, hydrocarbons compounds seem to have a limited contribution to the antifungal activity, as is mentioned in the literature $[10,11]$. In view of these considerations, the deterpenation process is an effective choice to increase the yields of oxygenated terpenes and to remove hydrocarbons (terpeneless EOs), which enhances the quality of EOs with regards to its biological activity. Moreover, this could promote their commercial value and even step up the possibility of upscaling the process [12].

The aim of this work was to study the chemical profile of Carum carvi L. and Origanum majorana L. EOs and their fractions were obtained with vacuum distillation. Further, we investigated relations between free-terpenes hydrocarbons fractions and major components and their antifungal effect. The main focus was to examine the inhibitory effects of these essential oils before and after the deterpenation process in order to identify the responsible terpenes of antifungal activity against Rizopus (R. oryzae and R. stolonifier) and Aspergillus (A. penicillioides) fungal strains. To the best of our knowledge, this is the first study that provides terpenless caraway essential oil with high purity of (-)-carvone $97.15 \pm 5.97 \%$ using the under reduced pressure steam distillation method.

\section{Results}

\subsection{Chemical Composition of EOs and Their Fractions}

The results from the GC-MS analyses are reported in Table 1. The identification was established using the retention time lock (RTL) and the mass-to-charge ratio $(\mathrm{m} / \mathrm{z})$ of the largest peaks. The compounds quantification was based on the normalized peak area without using correction factors. The chemical results of MEO and its fractions were a part of our previous published work [10], which demonstrates that reduced pressure steam distillation was an effective method used to obtain deterpenated fractions from Origanum majorana L. essential oil. The interesting results of this simple green technique allowed us to test it on Carum carvi L., then to compare between MEO and CEO chemical compositions.

The main components of the EOs were monoterpenes, while sesquiterpenes and other compounds were found in a small amount. However, there were similarities only within each EO and its fractions but not similarities between the dominant components of $\mathrm{MEO}$ and CEO.

Caraway essential oil (CEO) was dominated by oxygenated monoterpenes (77.43\%) followed by monoterpene hydrocarbons $(22.48 \%$ ) without any trace of sesquiterpenes. Within the oxygenated monoterpenes, (-)-carvone (74.25\%) was the main compound. Among the monoterpene hydrocarbons, D-limonene $(22.22 \%)$ was dominant.

On the other hand, the main compounds found in the marjoram essential oil (MEO) were terpin-4-ol (27.32\%), $\gamma$-terpinene (15.73\%), and $\alpha$-terpinene $(11.08 \%)$. This EO contained a complex mixture of oxygenated monoterpenes (47.36\%), monoterpene hydrocarbons (50.70\%), and a small amount of sesquiterpenes hydrocarbons (4.94\%).

Regarding the CEO fractions, nine compounds were identified in the first fraction $\left(\mathrm{CF}_{1}\right)$, in which D-limonene $(77.35 \%),(-)$-carvone $(20.18 \%)$, and $\beta$-myrcene $(1.54 \%)$ were the major components. Moreover, the composition of the second fraction $\left(\mathrm{CF}_{2}\right)$ displayed the same chemotype as the CEO but with slight proportional differences. The third fraction $\left(\mathrm{CF}_{3}\right)$ was composed of 13 constituents but was mainly dominated by (-)-carvone $(97.15 \%)$. 
Table 1. Chemical composition of essential oils and fractions identified by the gas chromatography-mass spectrometry (GC-MS).

\begin{tabular}{|c|c|c|c|c|c|c|c|c|c|c|}
\hline \multirow{2}{*}{ Compounds } & \multirow{2}{*}{$m / z$} & \multirow{2}{*}{ RT } & CEO & CF1 & CF2 & CF3 & MEO & MF1 & MF2 & MF3 \\
\hline & & & $(\%)$ & $(\%)$ & $(\%)$ & $(\%)$ & $(\%)$ & $(\%)$ & $(\%)$ & $(\%)$ \\
\hline$\beta$-terpinen & $93 / 77 / 79$ & 5.72 & $0.03 \pm 0.02$ & $0.08 \pm 0.03$ & - & - & - & - & - & - \\
\hline$\beta$-myrcen & $93 / 69 / 41$ & 5.91 & $0.18 \pm 0.02$ & $1.54 \pm 0.25$ & $1.15 \pm 0.19$ & - & - & - & - & - \\
\hline 2-tujene & 93/9177 & 6.21 & - & - & - & - & $2.24 \pm 0.42$ & $4.12 \pm 1.04$ & - & - \\
\hline$\alpha$-pinene & $93 / 91 / 92$ & 6.39 & $0.05 \pm 0.02$ & $0.14 \pm 0.02$ & $0.05 \pm 0.01$ & $0.49 \pm 0.08$ & $0.87 \pm 0.16$ & $1.61 \pm 0.25$ & - & - \\
\hline D-limonene & $68 / 93 / 67$ & 6.55 & $22.22 \pm 2.13$ & $77.32 \pm 4.01$ & $18.31 \pm 1.96$ & $0.07 \pm 0.01$ & - & - & - & - \\
\hline camphene & $93 / 121 / 79$ & 6.79 & - & - & - & - & $0.08 \pm 0.05$ & - & - & - \\
\hline 4(10)-Thujene & $41 / 94 / 69$ & 7.52 & - & - & - & - & $5.53 \pm 0.41$ & $11.17 \pm 1.03$ & - & - \\
\hline$\beta$-pinene & $28 / 32 / 93$ & 7.60 & - & - & - & - & $0.46 \pm 0.07$ & $0.90 \pm 0.09$ & - & - \\
\hline $1 R, 4 R$ - $p$-mentha-2,8-dienol & $109 / 79 / 94$ & 7.97 & $0.20 \pm 0.02$ & $0.15 \pm 0.01$ & $0.30 \pm 0.05$ & $0.15 \pm 0.03$ & - & - & - & - \\
\hline myrcene & 28/93/41 & 8.05 & - & - & - & - & $1.62 \pm 0.09$ & $2.77 \pm 0.88$ & - & - \\
\hline cis-p-Mentha-2,8-dien-1-ol & $134 / 109 / 43$ & 8.22 & $0.34 \pm 0.06$ & $0.06 \pm 0.00$ & $0.44 \pm 0.06$ & $0.14 \pm 0.04$ & - & - & - & - \\
\hline limonene oxide & $43 / 94 / 67$ & 8.29 & $0.07 \pm 0.00$ & - & $0.39 \pm 0.10$ & $0.03 \pm 0.00$ & - & - & - & - \\
\hline$\alpha$-phellandrene & 93/91/77 & 8.44 & - & - & - & - & $0.58 \pm 0.11$ & $0.95 \pm 0.14$ & - & - \\
\hline 2-nonenal & $55 / 28 / 41$ & 8.64 & $0.04 \pm 0.00$ & - & $0.07 \pm 0.02$ & - & - & - & - & - \\
\hline camphenone & $93 / 108 / 91$ & 8.85 & $0.05 \pm 0.00$ & - & $0.07 \pm 0.01$ & $0.04 \pm 0.01$ & - & - & - & - \\
\hline$\alpha$-terpinene & $121 / 93 / 136$ & 8.87 & - & - & - & - & $11.08 \pm 0.88$ & $21.15 \pm 4.52$ & $1.48 \pm 0.00$ & $0.18 \pm 0.00$ \\
\hline$\beta$-phellandrene & $93 / 77 / 91$ & 9.23 & - & - & - & - & $4.36 \pm 0.25$ & $7.81 \pm 0.78$ & $0.87 \pm 0.06$ & $0.51 \pm 0.07$ \\
\hline$\gamma$-terpinene & $93 / 91 / 136$ & 10.27 & - & - & - & - & $15.73 \pm 1.20$ & $27.53 \pm 2.45$ & $7.08 \pm 1.02$ & - \\
\hline carveol & $84 / 109 / 134$ & 10.33 & $1.55 \pm 0.13$ & - & $0.65 \pm 0.07$ & $0.32 \pm 0.02$ & - & - & - & - \\
\hline trans-sabinene hydrate & & 10.47 & - & - & - & - & $1.58 \pm 0.24$ & $1.30 \pm 0.07$ & $2.84 \pm 0.17$ & $0.44 \pm 0.07$ \\
\hline 7dihydrocarveol & $93 / 107 / 121$ & 10.49 & $0.22 \pm 0.02$ & - & $0.17 \pm 0.03$ & $0.67 \pm 0.09$ & - & - & - & - \\
\hline (-)-Carvone & $82 / 108 / 93$ & 11.07 & $74.25 \pm 4.25$ & $20.18 \pm 1.63$ & $78.21 \pm 3.69$ & $97.15 \pm 5.97$ & - & - & - & - \\
\hline$\alpha$-Terpinolene & & 11.20 & - & - & - & - & $3.82 \pm 0.56$ & - & $2.03 \pm 1.11$ & $3.43 \pm 0.89$ \\
\hline cis-sabinene hydrate & & 11.53 & - & - & - & - & $4.52 \pm 0.76$ & $1.88 \pm 0.30$ & $10.00 \pm 1.56$ & $5.79 \pm 0.78$ \\
\hline linalool & $71 / 28 / 93$ & 11.60 & - & - & - & - & $1.16 \pm 0.09$ & $0.39 \pm 0.01$ & $1.82 \pm 0.77$ & $0.67 \pm 0.22$ \\
\hline perilla aldéhyde & $135 / 77 / 93$ & 11.82 & $0.21 \pm 0.02$ & - & $0.22 \pm 0.10$ & $0.67 \pm 0.14$ & - & - & - & - \\
\hline trans- $p$-menth-2-enol & & 12.30 & - & - & - & - & $2.05 \pm 0.02$ & - & $3.13 \pm 0.92$ & $1.90 \pm 0.41$ \\
\hline cis- $\beta$-Terpineol & 28/43/93 & 12.92 & - & - & - & - & $1.36 \pm 0.33$ & $0.52 \pm 0.09$ & $1.86 \pm 0.20$ & $2.76 \pm 0.38$ \\
\hline endo-borneol & & 13.85 & - & - & - & - & $0.23 \pm 0.04$ & - & - & $0.46 \pm 0.05$ \\
\hline thymol & $135 / 150 / 91$ & 14.23 & - & - & - & - & $\begin{array}{c}- \\
-\end{array}$ & - & - & $0.30 \pm 0.06$ \\
\hline terpine-4-ol & $71 / 111 / 93$ & 14.35 & - & - & - & - & $27.32 \pm 2.21$ & $7.30 \pm 1.22$ & $54.39 \pm 3.25$ & $48.60 \pm 4.87$ \\
\hline$\beta$-fenchyl alcohol & & 14.40 & - & - & - & - & - & - & $9.63 \pm 1.54$ & $23.84 \pm 2.39$ \\
\hline p-cymen-8-ol & & 14.50 & - & - & - & - & $0.08 \pm 0.00$ & - & - & - \\
\hline
\end{tabular}


Table 1. Cont

\begin{tabular}{|c|c|c|c|c|c|c|c|c|c|c|}
\hline \multirow{2}{*}{ Compounds } & \multirow{2}{*}{$m / z$} & \multirow{2}{*}{ RT } & \multirow{2}{*}{$\begin{array}{r}\text { CEO } \\
(\%)\end{array}$} & \multirow{2}{*}{$\begin{array}{l}\text { CF1 } \\
(\%)\end{array}$} & \multirow{2}{*}{$\begin{array}{l}\text { CF2 } \\
(\%)\end{array}$} & \multirow{2}{*}{$\begin{array}{l}\text { CF3 } \\
(\%)\end{array}$} & \multirow{2}{*}{$\begin{array}{c}\text { MEO } \\
(\%)\end{array}$} & \multirow{2}{*}{$\begin{array}{c}\text { MF1 } \\
(\%)\end{array}$} & \multirow{2}{*}{$\begin{array}{c}\text { MF2 } \\
(\%)\end{array}$} & \multirow{2}{*}{$\begin{array}{c}\text { MF3 } \\
(\%) \\
\end{array}$} \\
\hline & & & & & & & & & & \\
\hline trans-piperitol & & 14.81 & - & - & - & - & $0.64 \pm 0.04$ & - & $0.57 \pm 0.07$ & $2.61 \pm 0.37$ \\
\hline cis-piperitol & 28/32/18 & 15.17 & - & - & - & - & $0.73 \pm 0.09$ & - & $0.82 \pm 0.04$ & $1.79 \pm 0.11$ \\
\hline caryophyllene & $133 / 93 / 91$ & 20.78 & - & - & - & - & $0.83 \pm 0.07$ & - & $0.80 \pm 0.04$ & $2.70 \pm 0.44$ \\
\hline aromandendrene & & 21.23 & - & - & - & - & $0.05 \pm 0.00$ & - & - & $0.33 \pm 0.10$ \\
\hline$\alpha$-humulene & & 21.55 & - & - & - & - & $0.05 \pm 0.01$ & - & - & - \\
\hline (+)-Bicyclogermacrene & 28/32/18 & 22.50 & - & - & - & - & $0.65 \pm 0.20$ & - & - & $1.68 \pm 0.17$ \\
\hline spathulenol & $43 / 41 / 205$ & 24.18 & - & - & - & - & $0.24 \pm 0.04$ & - & - & $0.20 \pm 0.02$ \\
\hline caryophylleneoxide & 79/43/93 & 24.30 & - & - & - & - & $0.15 \pm 0.00$ & - & - & - \\
\hline linalylacetate & $93 / 28 / 43$ & 16.60 & - & - & - & - & $0.56 \pm 0.10$ & - & $0.65 \pm 0.09$ & $1.23 \pm 0.22$ \\
\hline Isobornyl acetate & 28/32/95 & 17.41 & - & - & - & - & $0.26 \pm 0.02$ & - & & $0.41 \pm 0.03$ \\
\hline$\alpha$-terpenylpropionate & & 17.61 & - & - & - & - & - & - & $1.39 \pm 0.21$ & - \\
\hline 4-Terpinenyl acetate & $93 / 121 / 136$ & 17.81 & - & - & - & - & $1.03 \pm 0.18$ & - & - & - \\
\hline \multicolumn{2}{|c|}{ Mass $(\mathrm{g})$} & & 20.12 & 4.1 & 5.62 & 10.40 & 22.00 & 8.88 & 10.13 & 0.99 \\
\hline \multicolumn{2}{|c|}{ Boiling temperature (at $10 \mathrm{mmHg}$ ) } & & - & $65-75$ & $80-90$ & 110 & - & $52-54$ & $70-72$ & $84-86$ \\
\hline \multirow{2}{*}{\multicolumn{2}{|c|}{$\begin{array}{l}\text { Total terpenes hydrocarbons }(\%) \\
\text { Total oxygenated terpenes }(\%)\end{array}$}} & & 22.48 & 79.06 & 19.47 & 0.56 & 50.70 & 87.92 & 12.90 & 8.98 \\
\hline & & & 77.43 & 21.62 & 79.21 & 98.56 & 47.36 & 12.05 & 85.06 & 88.86 \\
\hline
\end{tabular}


In the case of the $\mathrm{MEO}$ fractions, fifteen compounds were identified in the first fraction $\left(\mathrm{MF}_{1}\right)$, whereas $\gamma$-terpinene $(27.53 \%), \alpha$-terpinene $(21.15 \%)$, and $4-(10)$-thujene $(11.17 \%)$ represented the major components. In the second fraction $\left(\mathrm{MF}_{2}\right), 17$ constituents were identified with terpinen-4-ol $(54.39 \%)$, cis-sabinene hydrate $(10.00 \%)$, and $\beta$-fenchyl alcohol $(9.63 \%)$ as the main components. Finally, 21compounds were found on the third fraction $\left(\mathrm{MF}_{3}\right)$, mainly represented by terpinen-4-ol (48.60\%), cis- $\beta$-fenchyl alcohol (23.84\%), and cis-sabinene hydrate $(5.79 \%)$.

\subsection{Antifungal Effect of EOs and Fractions}

All fruit spoilage fungi were isolated using the agar plate method (APM) and identified as follows: Rhizopus oryzae from pumpkins, Rhizopus stolonifier from peaches, and Aspergillus penicillioides from prunes (Figure 1). The identification was based on their growth and morphological characteristics.
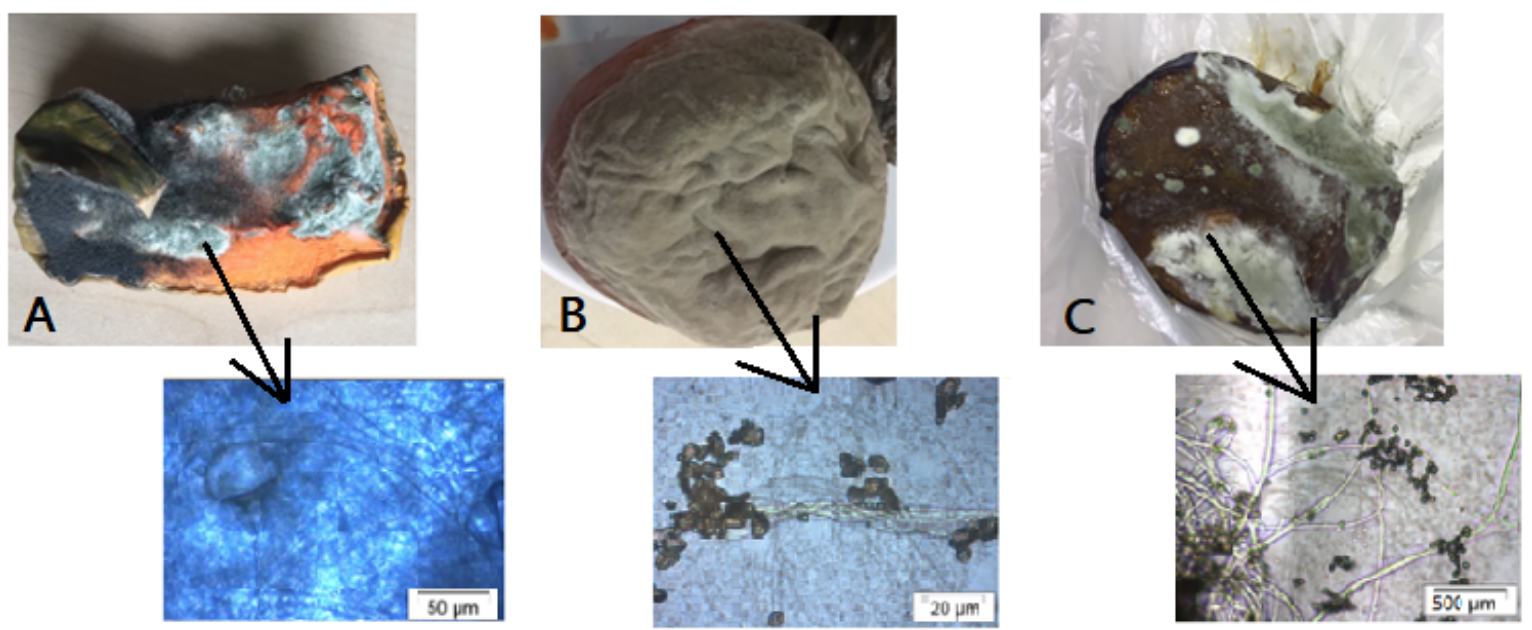

Figure 1. Spoilage fungi: (A) R. oryzae from pumpkins, (B) R. stolonifier from peaches, and $(\mathbf{C})$ A. penicillioides form prunes.

After seven days of fungal exposition, the percentage of growth inhibition (FGI \%) was considerable in the $\mathrm{CEO}$ and its fractions $\mathrm{CF}_{2}$ and $\mathrm{CF}_{3}$, in addition to the $\mathrm{MEO}$ and its fractions $\mathrm{MF}_{2}$ and $\mathrm{MF}_{3}$. The values are listed in Table 2; a visual appearance is shown in Figure 2.

Table 2. Fungal growth inhibition (FGI \%) of CEO and MEO against R. oryzae, R. stolonifier, and A. penicillioides.

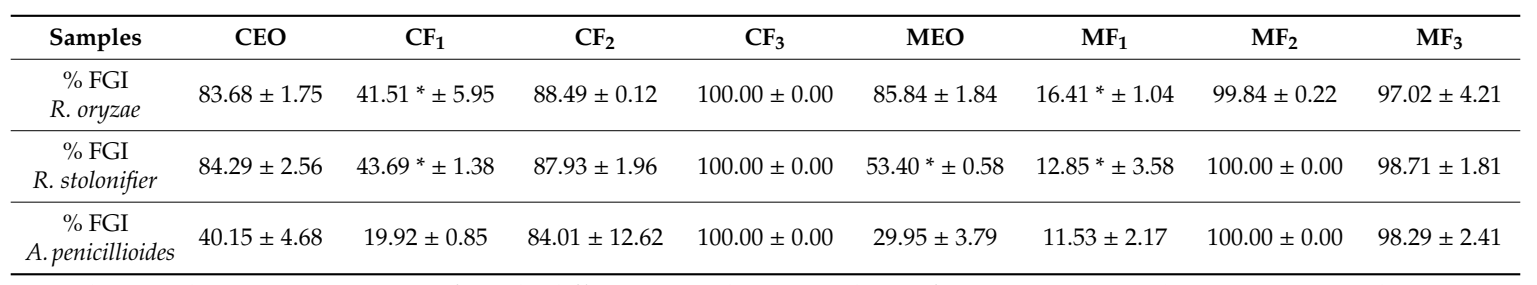

The population means are significantly different according to analysis of variance (ANOVA) one-way test at the 0.01 level. * The difference of the means is significant at the 0.01 level when comparing with all samples, according to Bonferroni and Tukey tests. 


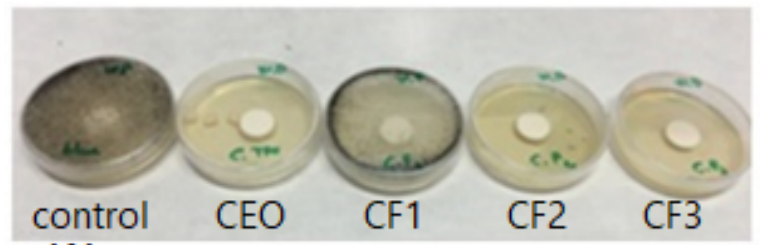

(A)

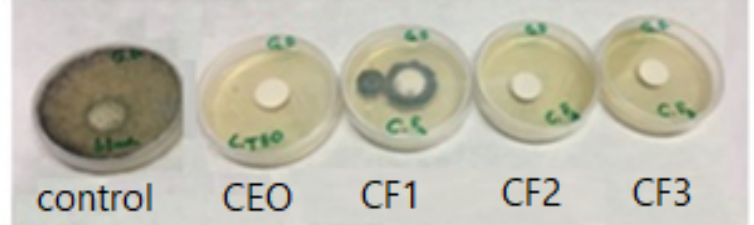

(B)

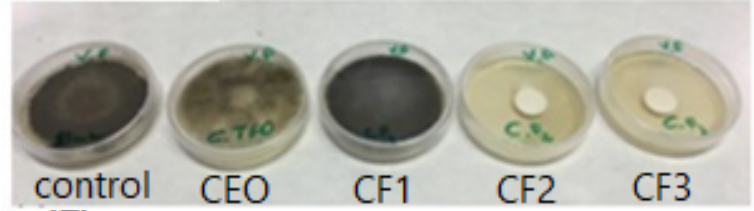

(E)

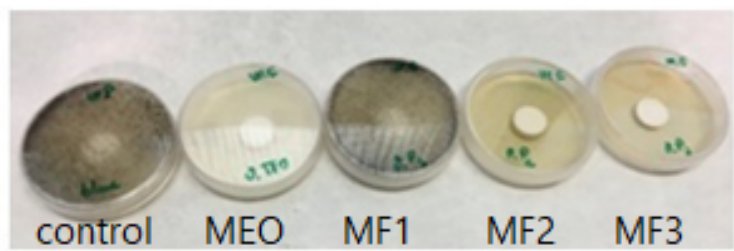

(D)

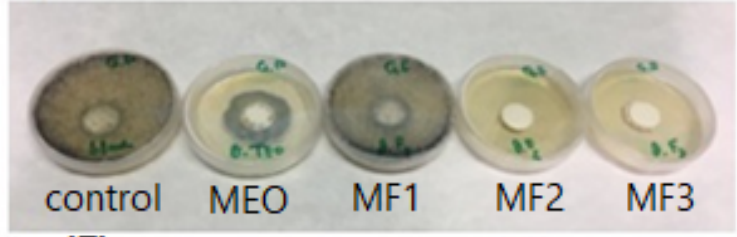

(E)

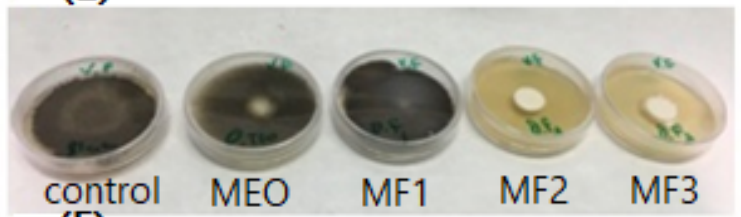

(F)

Figure 2. Visual observation of fungal growth inhibition (FGI) of Carum carvi L. essential oil (CEO) and its fractions against (A) R. oryzae, (B) R. stolonifier, and (C) A. penicillioides. FGI of Origanum majorana L. essential oil (MEO) and its fractions against (D) R. oryzae, (E) R. stolonifier, and (F) A. penicillioides. Media after seven days at $27 \pm 1.5^{\circ} \mathrm{C}$.

The values of inhibition were more than $50 \%$ when both Rhizopus strains (oryzae and stolonifier) were inoculated. In the case of the Aspergillus strain, there was found that only the fractions $\mathrm{CF}_{2}, \mathrm{CF}_{3}$, $\mathrm{MF}_{2}$, and $\mathrm{MF}_{3}$ showed more than $50 \%$ of FGI, being this strain more aggressive than Rhizopus.

\section{Discussion}

The EOs selected for this study contained one or two active compounds. This differs from other studies, which is likely due to geographical location, a plant's adaptive metabolism, harvest time, and extraction conditions [13-16]. These results are similar to those found by Laribi et al. [15], in which (-)-carvone $(76.37 \pm 4.73 \%)$ and D-limonene $(19.52 \pm 3.31 \%)$ were found to be the main component of Tunisian CEO. However, other studies showed different results. For example, German and Sweden CEO present high yields of limonene (about 70\%) followed by carvone [15,17]. Moreover, Egyptian CEO present the dominance of (-)-carvone (48.70\%) followed by limonene (24.20\%) [18].

The goal was to fractionate the raw oils to obtain their free-terpene hydrocarbon fractions. In fact, the instability of terpene hydrocarbons to heat and light seems to be overshadowing the potential benefits of various essential oils. Thus, it is common industrial practice to remove some or all of the terpene hydrocarbons to concentrate the oxygenate terpenes in the EO. This important operation is referred to as the deterpenation process and obtained fractions are referred to as folded, terpeneless, or deterpenated oils [19-21].

Therefore, it was possible to test the bioactivity of the obtained terpenless EO regarding their chemical composition. The quantitative and qualitative differences of the EOs fractions were evident and the antifungal capacity varied according to the distribution of the components of each fraction.

The GC-MS results showed the increase of the proportion of oxygenated compounds in some EO fractions: $\mathrm{CF}_{2}(79.21 \%), \mathrm{CF}_{3}(98.56 \%), \mathrm{MF}_{2}(85.06 \%)$, and $\mathrm{MF}_{3}(88.86 \%)$. Therefore, these were considered as the free-terpene hydrocarbons fractions. With regards to the raw EOs, the CEO could be considered as rich oxygenated but the MEO is moderately oxygenated. The remaining fractions $\mathrm{CF}_{1}$ and $\mathrm{MF}_{1}$ presented very poor oxygenated compounds but high amount of monoterpene hydrocarbons $(79.06 \%$ and $87.92 \%$, respectively). These results were similar to those found in previous 
studies [14,21,22]. Dissimilar results were reported by Laribi et al. (2010) [23], where the terpinene-4-ol chemotype was presented in the cis-sabinene hydrate or in combination with $p$-cymene.

The obtaining of high purity (-)-carvone $97.15 \pm 5.97 \%$ could be considered as an important finding given it has been the subject of extensive research [14]. This fact is of great economic interest due to carvone's application as a fragrance, flavor, potato sprouting inhibitor, and antimicrobial agent. It also has applications in the medical field [23].

Regarding the fungal strains used in this study, they were chosen because they commonly appear as food spoilage agents. Specifically, the genders Rhizopus and Aspergillus are the most common agents that deteriorate food $[14,16]$. Considering that our antifungal results showed that the clearest inhibitory effect occurs in the free-terpene hydrocarbons fractions $\mathrm{CF}_{3}, \mathrm{MF}_{2}, \mathrm{and}_{\mathrm{MF}}$ with values above $97 \%$ against all the strains. This effect could be attributed to the oxygenated terpenes compounds, which represent $98.56 \%\left(\mathrm{CF}_{3}\right), 85.06 \%\left(\mathrm{MF}_{2}\right)$, and $88.86 \%\left(\mathrm{MF}_{3}\right)$ of their chemical composition. The results reveal that among all terpene compounds present in the EOs, the oxygenated are those that present higher antifungal activity. Other studies relate oxygenated compounds to bioactivity $[3,10,23]$. The physical nature of the rich oxygenated EOs, such as their low molecular weights combined with a lipophilic character, allow them to penetrate the cell membrane more quickly than other substances [8,9]. Conversely, the rich monoterpene hydrocarbons fractions $\mathrm{CF}_{1}(80.49 \%)$ and $\mathrm{MF}_{1}(87.92 \%)$ in which the principal compounds were $\gamma$-terpinene, $p$-cymene, $\alpha$-pinene, $\beta$-pinene, and limonene exhibited moderate antifungal activities. These results shown that the monoterpenes hydrocarbons possess a limited antifungal potential, which is a conclusion also discussed by other authors [8,23].

According to Morcia et al. 2012 [11], the general classification of the antifungal activity of the compounds present in the EOs from the higher to the lower, show the following order: phenols > aldehydes $>$ ketones $>$ alcohols $>$ esters $>$ hydrocarbons. Therefore, the correlation between the higher antifungal activity and the fractions $\mathrm{MF}_{2}$ and $\mathrm{MF}_{3}$ is evident, with the presence of a high percentage of alcohols related compounds, such as terpin-4-ol (54.39\% and 48.60\%, respectively). This is in agreement with other studies, which found that terpinen-4-ol were the primary active components of the EOs $[3,11]$.

In general, the bioactivities of any EO are decided by either one or two of its main components [24]. Thus, the high percentage of (-)-carvone in $\mathrm{CEO}(74.25 \%)$ and its fractions $\mathrm{CF}_{2}(78.21 \%)$ and $\mathrm{CF}_{3}$ $(97.15 \%)$ could be responsible for the high antifungal effect. These results cohered with published data that reported how carvone has been shown to be a biologically active component of Tunisian caraway essential oils. It can be a potato sprouting inhibitor $[25,26]$, antimicrobial agent $[18,26]$, and applied in the medical field [23].

In another set of results, inhibitions against $R$. oryzae and $R$. stolonifier for both CEO (83.68 and $84.29 \%$ ) and MEO (85.84 and 53.40\%) could be considerable in comparison with treated fractions $\mathrm{CF}_{2}$ (88.49 and $87.93 \%), \mathrm{CF}_{3}$ (100\% both), $\mathrm{MF}_{2}$ (99.84 and 100\%), and $\mathrm{MF}_{3}$ (97.02 and 98.71\%). This might be related to the quantity of the main component of each essential oil CEO (carvone: $74.25 \%$ ) and MEO (terpine-4-ol: 27.32\%). These two last cited terpenes known to have pronounced antimicrobial activities, but their actions depended on the synergistic effect with other constituents of the essential oils $[11,18,27]$. However, the same conclusion cannot be made for the CEO and MEO inhibition against A. penicillioides. The above findings show that the Rhizopus and Aspergillus fungus families express different behaviors towards the same tested essential oils. Moleyar and Narasimham demonstrated that susceptibility or resistance of a fungus to the antifungal activity of an essential oil depends on the capacity of the fungus to detoxify their main compounds [28]. Thus, Aspergillus and Rhizopus indicated dissimilar detoxification behavior toward terpinene-4-ol and carvone. This could explain different measured inhibition values. Many parameters affect the relative capacities of the two fungus to detoxify the compounds as enzyme content, microbial transformation, or degradation of antifungal compounds and the mechanism involved [28,29]. 


\section{Materials and Methods}

\subsection{Solvents and Reagents}

The following reagents were used: Ethyl acetate (high performance liquid chromatography (HPLC) grade, chemical abstracts service (CAS) $\mathrm{N}^{\circ}$ A4A-78-6, purity 99.98\%, Fisher chemical Scientific, Loughborough, UK); Lactophenol blue solution ( $\mathrm{N}^{\circ}$ 61335, Panreac, Barcelona, Spain); potato dextrose agar (PDA, CAS N 01-483-500, Eur; Pharm., Scharlab Microbiology, Barcelona, Spain); and Aspergillus niger (A. niger, Tiegh MB284309, CBS-KNAW, Utrecht, The Netherlands).

\subsection{Essential Oils Extraction}

In July 2015, fresh plant material, including twigs, leaves, and flowers of marjoram (Origanum majorana L.) were collected in Sidi Bouzid, Tunisia. In July 2017, seeds of caraway (Carum carvi L.) were collected from cultivated plants in the region of Nabeul, Tunisia. These species were verified by the senior taxonomist, Dr. Ridha El Mokni (Laboratory of Botany and Plant Ecology, University of Carthage, Carthage, Tunisia), who confirmed the taxonomic identification of the plant material.

The plant material was deposited in clean and dry plastic bags and processed immediately for the isolation of essential oils. The extraction method was done with a Clevenger apparatus (Fisher Scientific, Toledo, Spain) according to the description of British Pharmacopoeia (1980). From each plant, $400 \mathrm{~g}$ were extracted with $3 \mathrm{~L}$ distilled water for $3 \mathrm{~h}$ at $373.15 \mathrm{~K}$. The collected essential oils were dried under anhydrous sulfate and then stored at $4{ }^{\circ} \mathrm{C}$ for further analysis. Hydrodistillation of Origanum majorana L. essential oil (MEO) and Carum carvi L. essential oil (CEO) yielded $1.7 \%$ and $2.8 \%$ $(w / w)$, respectively. Each extraction was performed at least three times and the standard deviation of the procedure was recorded within the results. The collected data were statistically analyzed according to the normality and homogeneity values of variances by a multiple comparison procedure analysis of variance (ANOVA).

\subsection{Deterpenation Process}

The deterpenation process was carried out according to the method described by Ben Salha et al. (2017) [10]. CEO and MEO were subjected to the vacuum distillation process under different boiling temperatures. Each EO was placed in a boiling flask (capacity $50 \mathrm{~mL}$ ) and the separation level of the mixture compounds was checked according to the boiling temperature at the top of the column. The constant value was kept at $10 \mathrm{kPa}$. The distillation was performed until the volume in the flask was totally reduced. The collected samples were analyzed using the gas chromatography-mass spectrometry (GC-MS) technique.

\subsection{Identification and Quantification of EOs and Their Fractions}

The equipment used for the chemical identification was a gas chromatograph coupled with an Agilent 5975C mass spectrometry detector (Agilent Technologies, Inc., Santa Clara, CA, USA) equipped with ionization voltage in the EI-mode (70 eV 166). The oven temperature program was $60{ }^{\circ} \mathrm{C}$ rising at $2{ }^{\circ} \mathrm{C} / \mathrm{min}$ to a final temperature of $280{ }^{\circ} \mathrm{C}$. The functional conditions were: let mode: $10: 1$; flow rate: $0.7 \mathrm{~mL} / \mathrm{min}$; carrier gas: $\mathrm{N}_{2}$; and injection volume: $10 \mu \mathrm{L}$ of essential oil dissolved in $1 \mathrm{~mL}$ of ethyl acetate (HPLC grade, CAS N ${ }^{\circ}$ A4A-78-6, purity 99.98\%, Fisher chemical Scientific, Loughborough, UK). The compounds were identified by their retention times [30] using the NIST Mass Spectral Search Program (Mass Spectral Library version 2.2, 2017, National Institute of Standards and Technology (NIST), Gaithersburg, MD, USA). The quantification of each peak was performed by the mass reported. The results were expressed as a percentage $(w / w)$. 


\subsection{Isolation of Food Spoilage Fungi}

The microorganisms used in this study were isolated from pumpkins, peaches, and prunes, which are available in any market. The isolation method of fungi was previously described by Toma and Abdulla 2013 and Romero et al. 2005 with some modifications [31,32]. The sub-culturing of the fungal colony was carried out using a sterile fresh medium of potato dextrose agar (PDA CAS $\mathrm{N}^{\circ}$ 01-483-500, Eur; Pharm., Scharlab Microbiology, Barcelona, Spain) and incubating at $27^{\circ} \mathrm{C}$ until fungal proliferation occurred on the medium surface. The isolation in the culture medium was performed by three replicates.

\subsection{Identification of the Isolated Fungi}

The identification was made according to taxonomic keys based on "habit characters" [16]. The isolated fungi were subjected to morphological and optical studies using microscopic techniques, as well as using an imaging processing and quantification system (Cellometer ${ }^{\circledR}$ Mini and automatic cell counter, Nexcelom Bioscience LLC., Lawrence, MA, USA). The parameters taken into account in the identification were the growth rate, colony diameter, texture, color, reproductive structures, reverse pigmentation, among others [33,34].

\subsection{Antifungal Activity}

The evaluation of the antifungal activity of $\mathrm{MEO}, \mathrm{CEO}$, and their fractions was performed by the micro-atmosphere test, according to the protocol described by Ben Salha et al. [10]. Petri dishes (6 cm diameter) containing a PDA medium were aseptically inoculated with $40 \mu \mathrm{L}$ of each fungal suspension $\left(10^{6}\right.$ spores $/ \mathrm{mL}$ ). Sterile paper discs (Whatman filter paper grade 1 ) were impregnated with $5 \mu \mathrm{L}$ of each EO sample, placed on the agar media, and incubated at $27 \pm 1.5^{\circ} \mathrm{C}$. After seven days, the disc was extracted, washed, vortexed, and stained with Lactophenol blue solution to count the spore concentration on the discs with a Cellometer ${ }^{\circledR}$ Mini automated cell counter (Nexcelom Bioscience LLC., Lawrence, MA, USA). Each experiment was carried out twice. The fungi growth inhibition (FGI) was calculated as the concentration of spores per milliliter according to the following Equation (1):

$$
\text { FGI }(\%)=\frac{C_{c}-C_{i}}{C_{c}} \times 100
$$

$\mathrm{C}_{\mathrm{c}}$ is the average concentration in the control sample and $\mathrm{C}_{\mathrm{i}}$ is the average concentration in the treated one.

\subsection{Statistical Analysis}

The collected data were statistically analyzed according to the normality and homogeneity values' of variances by a multiple comparison procedure analysis of variance (ANOVA). The Bonferroni Significant Difference (BSD) and the Tukey test were applied after rejecting the null hypothesis. The software used for this statistical analysis was Origin 2017 (OriginLab Corporation, Northampton, MA, USA).

\section{Conclusions}

Vacuum distillation is an effective method to isolate oxygenated terpenes from carum and origanum EOs. This method found values of $79.21 \%, 98.56 \%, 85.06 \%$, and $88.86 \%$ in the fractions $\mathrm{CF}_{2}, \mathrm{CF}_{3}, \mathrm{MF}_{2}$, and $\mathrm{MF}_{3}$, respectively. Furthermore, it was found that these fractions presented the most substantial fungal growth inhibition against the tested strains and thus their bioactivity was directly connected with the high content of oxygenated compounds (alcohol: terpin-4-ol, and ketone: $(-)$-carvone). According to these results, these fractions rich in oxygenated compounds can be used in formulations as natural additives against food spoilage, as they present high extraction yields that are interesting for industrial applications. 
Author Contributions: G.B.S., R.H.D., J.L., O.L., and M.A. conceived and designed the experiments; G.B.S. and O.L. prepared the essential oils; G.B.S. prepared and determined the deterpenation process; G.B.S. and R.H.D. prepared and analyzed the GC-MS analysis; G.B.S. and R.H.D. determined the antifungal activity; G.B.S. and R.H.D. wrote the article.

Funding: This research was funded by Basque Government (IT 1008-16 and POS-2018-1-0077).

Acknowledgments: The authors are grateful for the financial support received from the Basque Government (IT 1008-16 and POS-2018-1-0077).

Conflicts of Interest: The authors declare no conflict of interest.

\section{References}

1. Essono, G.; Ayodele, M.; Akoa, A.; Foko, J.; Olembo, S.; Gockowski, J. Aspergillus species on cassava chips in storage in rural areas of southern Cameroon: Their relationship with storage duration, moisture content and processing methods. African J. Microbiol. Res. 2007, 1, 1-8.

2. Mohamed Abdel-Kader, M.; Samy El-Mougy, N.; Mohamed Lashin, S. Essential oils and trichoderma harzianum as an integrated control measure against faba bean root rot pathogens. J. Plant Prot. Res. 2011, 51, 306-313. [CrossRef]

3. Stević, T.; Berić, T.; Šavikin, K.; Soković, M.; Godevac, D.; Dimkić, I.; Stanković, S. Antifungal activity of selected essential oils against fungi isolated from medicinal plant. Ind. Crops Prod. 2014, 55, 116-122. [CrossRef]

4. Aligiannis, N.; Kalpoutzakis, E.; Mitaku, S.; Chinou, I.B. Composition and antimicrobial activity of the essential oils of two Origanum species. J. Agric. Food Chem. 2001, 49, 4168-4170. [CrossRef] [PubMed]

5. Aminifard, M.H.; Bayat, H. Antifungal Activity of Black Caraway and Anise Essential Oils Against Penicillium digitatum on Blood Orange Fruits. Int. J. Fruit Sci. 2018, 18, 307-319. [CrossRef]

6. Plavšić, D.V.; Dimić, G.R.; Psodorov, D.B.; Psodorov, D.D.; Šarić, L.Ć.; Čabarkapa, I.S.; Košutić, M.B. Antifungal activity of mentha piperita and carum carvi essential oils. Matica Srp. J. Nat. Sci. 2017, 133, 201-207. [CrossRef]

7. Griffin, S.G.; Wyllie, S.G.; Markham, J.L.; Leach, D.N. The role of structure and molecular properties of terpenoids in determining their antimicrobial activity. Flavour Fragr. J. 1999, 14, 322-332. [CrossRef]

8. De Lira Mota, K.S.; De Oliveira Pereira, F.; De Oliveira, W.A.; Lima, I.O.; De Oliveira Lima, E. Antifungal activity of thymus vulgaris 1 . essential oil and its constituent phytochemicals against Rhizopus oryzae: Interaction with ergosterol. Molecules 2012, 17, 14418-14433. [CrossRef]

9. Pawar, V.C.; Thaker, V.S. In vitro efficacy of 75 essential oils against Aspergillus niger. Mycoses 2006, 49, 316-323. [CrossRef]

10. Ben Salha, G.; Herrera Díaz, R.; Labidi, J.; Abderrabba, M. Deterpenation of Origanum majorana L. essential oil by reduced pressure steam distillation. Ind. Crops Prod. 2017, 109, 116-122. [CrossRef]

11. Morcia, C.; Malnati, M.; Terzi, V. In vitro antifungal activity of terpinen-4-ol, eugenol, carvone, 1,8-cineole (eucalyptol) and thymol against mycotoxigenic plant pathogens. Food Addit. Contam. Part A 2012, 29, 415-422.

12. Perini, J.F.; Silvestre, W.P.; Agostini, F.; Toss, D.; Pauletti, G.F. Fractioning of orange (Citrus sinensis L.) essential oil using vacuum fractional distillation. Sep. Sci. Technol. 2017, 52, 1397-1403. [CrossRef]

13. Brose, D.J.; Chidlaw, M.B.; Friesen, D.T.; LaChapelle, E.D.; Van Eikeren, P. Fractionation of citrus oils using a membrane-based extraction process. Biotechnol. Prog. 1995, 11, 214-220. [CrossRef]

14. Banchio, E.; Bogino, P.C.; Zygadlo, J.; Giordano, W. Plant growth promoting rhizobacteria improve growth and essential oil yield in Origanum majorana L. Biochem. Syst. Ecol. 2008, 36, 766-771. [CrossRef]

15. Laribi, B.; Kouki, K.; Bettaieb, T.; Mougou, A.; Marzouk, B. Essential oils and fatty acids composition of Tunisian, German and Egyptian caraway (Carum carvi L.) seed ecotypes: A comparative study. Ind. Crops Prod. 2013, 41, 312-318. [CrossRef]

16. Hashem, M.; Alamri, S. Contamination of common spices in Saudi Arabia markets with potential mycotoxin-producing fungi. Saudi J. Biol. Sci. 2010, 17, 167-175. [CrossRef] [PubMed]

17. Barnett, H.L.; Hunter, B.B. Illustrated Genera of Imperfect Fungi, 4th ed.; APS Press: St. Paul, MN, USA, 2013. 
18. Seo, S.-M.; Kim, J.; Lee, S.-G.; Shin, C.-H.; Shin, S.-C.; Park, I.-K. Fumigant Antitermitic Activity of Plant Essential Oils and Components from Ajowan (Trachyspermum ammi), Allspice (Pimenta dioica), Caraway (Carum carvi), Dill (Anethum graveolens), Geranium (Pelargonium graveolens), and Litsea (Litsea cubeba) Oils against Japanese Termite (Reticulitermes speratus Kolbe). J. Agric. Food Chem. 2009, 57, 6596-6602. [PubMed]

19. Salha, G.B.; Abderrabba, M.; Labidi, J. A status review of terpenes and their separation methods. Rev. Chem. Eng. 2019. [CrossRef]

20. Lago, S.; Rodríguez, H.; Soto, A.; Arce, A. Deterpenation of citrus essential oil by liquid-liquid extraction with 1-alkyl-3-methylimidazolium bis(trifluoromethylsulfonyl) amide ionic liquids. J. Chem. Eng. 2011, 56, 1273-1281. [CrossRef]

21. Hajlaoui, H.; Mighri, H.; Aouni, M.; Gharsallah, N.; Kadri, A. Chemical composition and in vitro evaluation of antioxidant, antimicrobial, cytotoxicity and anti-acetylcholinesterase properties of Tunisian Origanum majorana L. essential oil. Microb. Pathog. 2016, 95, 86-94. [CrossRef]

22. Sellami, I.H.; Maamouri, E.; Chahed, T.; Wannes, W.A.; Kchouk, M.E.; Marzouk, B. Effect of growth stage on the content and composition of the essential oil and phenolic fraction of sweet marjoram (Origanum majorana L.). Ind. Crops Prod. 2009, 30, 395-402. [CrossRef]

23. Laribi, B.; Kouki, K.; Mougou, A.; Marzouk, B. Fatty acid and essential oil composition of three Tunisian caraway (Carum carvi L.) seed ecotypes. J. Sci. Food Agric. 2010, 3, 391-396.

24. Raut, J.S.; Karuppayil, S.M. A status review on the medicinal properties of essential oils. Ind. Crops Prod. 2014, 62, 250-264. [CrossRef]

25. Şanl1, A.; Karadoğan, T. Carvone containing essential oils as sprout suppressants in potato (Solanum tuberosum L.) tubers at different storage temperatures. Potato Res. 2019, 3, 345-360. [CrossRef]

26. Shukla, S.; Pandey, S.S.; Chandra, M.; Pandey, A.; Bharti, N.; Barnawal, D.; Kalra, A. Application of essential oils as a natural and alternate method for inhibiting and inducing the sprouting of potato tubers. Food chem. 2019, 284, 171-179. [CrossRef]

27. Hromiš, N.; Lazić, V.; Bulut, S.; Popović, S.; Šuput, D.; Markov, S.; Tomović, V. Antimicrobial activity of composite chitosan biofilms with beeswax and caraway essential oil. J. Process. Energy Agric. 2017, 21, 76-80. [CrossRef]

28. Souza, E.L.D.; Lima, E.D.O.; Freire, K.R.D.L.; Sousa, C.P.D. Inhibitory action of some essential oils and phytochemicals on the growth of various moulds isolated from foods. Braz. Arch. Biol. Technol. 2005, 48, 245-250. [CrossRef]

29. Moleyar, V.; Narasimham, P. Detoxification of essential oil components (Citral and menthol) by Aspergillus niger and Rhizopus stolonifer. J. Sci. Food Agric. 1987, 39, 239-246. [CrossRef]

30. Adams, R.P.; Sparkman, O.D. Review of identification of essential oil components by gas chromatography/mass spectrometry. J. Am. Soc. Mass Spectrom. 2007, 18, 803-806.

31. Toma, F.M.; Abdulla, N.Q.F. Isolation and identification of fungi from spices and medicinal plants. Res. J. Environ. Earth Sci. 2013, 5, 131-138. [CrossRef]

32. Romero, S.M.; Comerio, R.M.; Larumbe, G.; Ritieni, A.; Vaamonde, G.; Fernández Pinto, V. Toxigenic fungi isolated from dried vine fruits in Argentina. Int. J. Food Microbiol. 2005, 104, 43-49. [CrossRef] [PubMed]

33. Pitt, J.I.; Hocking, A.D.; Ailsa, D. Fungi and Food Spoilage; Springer: New York, NY, USA, 2009.

34. Solberg, S.O.; Göransson, M.; Petersen, M.A.; Yndgaard, F.; Jeppson, S. Caraway essential oil composition and morphology: The role of location and genotype. Biochem. Syst. Ecol. 2016, 66, 351-357. [CrossRef]

Sample Availability: Samples of the compounds Carum carvi L. essential oil and Origanum majorana L. essential oil are available from the authors.

(C) 2019 by the authors. Licensee MDPI, Basel, Switzerland. This article is an open access article distributed under the terms and conditions of the Creative Commons Attribution (CC BY) license (http://creativecommons.org/licenses/by/4.0/). 